Şevket Gümüştekin ${ }^{\mathrm{a}}$, Ali Topal ${ }^{\mathrm{b}}$, Burak Şengöz ${ }^{\mathrm{b}}$

${ }^{a}$ Izmir Institute of Technology, Department of Electrical \& Electronics Engineering, Izmir, Turkey

${ }^{\mathrm{b}}$ Dokuz Eylul University, Faculty of Engineering, Department of Civil Engineering, Izmir, Turkey

\title{
Texture analysis of polymer modified bitumen images
}

This study aims to analyze the textural features extracted from microscopic images of elastomeric and plastomeric type polymer modified bitumen (PMB) including five different types and contents of polymers. Fluorescence microscopy was used to capture microscopic images from thin films of PMB samples at different magnification scales $(400 \times, 100 \times$, and $40 \times)$. Gabor filters were utilized to extract the textural features of bitumen images. The features were used in three different query tests to quantify their representation capacity. The $\mathrm{K}$ nearest neighbor classifier was tested using leave-one-out cross validation. Textural analysis on the captured images provided numerical results that are in compliance with subjective visual tests.

Keywords: Polymer modified bitumen; Microscopic image; Texture analysis; Gabor filters

\section{Introduction}

The enhancement in the level of living conditions due to social and economic development has increased the demand for safe and comfortable road surfaces with a higher driving quality during the last three decades. It is obvious that this demand can only be satisfied with road design procedures aiming flexible road surfaces with a longer service life. In order to construct long lasting road surfaces and to minimize deterioration such as permanent deformation, low temperature and fatigue cracking and moisture susceptibility, major emphasis has been placed on improving the performance of bituminous mixtures. This change in focus has led to a fundamental variation in the design of bituminous road surfaces such as improved bitumen characteristics. In order to improve bitumen characteristics, specific performance enhancers have been investigated. These include additive modification, polymer modification and chemical reaction modification [1].

The polymers that are used for bitumen modification can be divided into two main groups, named as elastomers and plastomers [2]. Within the elastomeric group, styrene butadiene styrene (SBS) block copolymers and within the plastomeric group, ethylene vinyl acetate (EVA) and ethylene butyl acrylate (EBA) have shown the greatest potential when blended with base bitumen [3]. Desirable characteristics of polymer modified bitumen (PMB) include greater elastic recovery, viscosity, cohesive strength, ductility and a higher softening point $[4,5]$.
Fluorescent microscopy has been used for the determination of the quality of the dispersion of PMB for many years. The captured images have been used for a subjective judgment of the quality of the PMB comparison with other images of PMBs. This method does not give much information to the PMB producers and additional tests must be performed to determine the quality of PMBs. The visual investigation of the images is concerned with the textures that are due to different dispersion characteristics which can be related to chemical and physical properties. In order to eliminate the need for subjective evaluations, texture analysis methods can be utilized to achieve automatic visual inspection.

Extraction of textural features from captured images and using these features for various classification problems have been widely studied [6]. These studies target many different applications that utilize image understanding to solve specific problems. This paper aims to analyse the textural properties of plastomeric and elastomeric type of PMB images using Gabor filters.

\section{Preparation of polymer modified bitumen samples}

The EBA (Elvaloy $\left.{ }^{\circledR} 3427\right)$, EVA (Evatene ${ }^{\circledR} 2805$, Elvaloy ${ }^{\circledR}$ 4170), and SBS (Kraton ${ }^{\circledR}$ D1101, Soltene ${ }^{\circledR}$ 6302) modified bitumen samples were prepared by means of a high and a low shear laboratory type mixer rotating at $1100 \mathrm{rpm}$ and $125 \mathrm{rpm}$, respectively [1, 2, 4, 7]. In preparation, the base bitumen was heated to fluid condition $\left(180-185^{\circ} \mathrm{C}\right)$, and poured into a $2000 \mathrm{ml}$ spherical flask. The EBA, EVA, and SBS polymers were then added slowly to the base bitumen.

The EBA and EVA concentrations in the base bitumen were chosen as $2 \%-6 \%$ and $3 \%-7 \%$ respectively according to the manufacturers. The concentrations of SBS in the base bitumen were also chosen as $2 \%$ to $6 \%$ by weight. The utilization of this content was based on past research made by Isacsson and Lu [7]. They concluded that a significant improvement in the properties of base bitumen was observed when the SBS content was increased from $2 \%$ to $6 \%$ by weight.

The temperature was kept constant at $185^{\circ} \mathrm{C}$, and the mixing process continued for $2 \mathrm{~h}$. The uniformity of dispersion of EBA, EVA and SBS in the base bitumen was confirmed by passing the mixture through an ASTM 100\# sieve. After completion, the samples were removed from the flask and divided into small containers, covered with aluminum foil and stored for testing. 


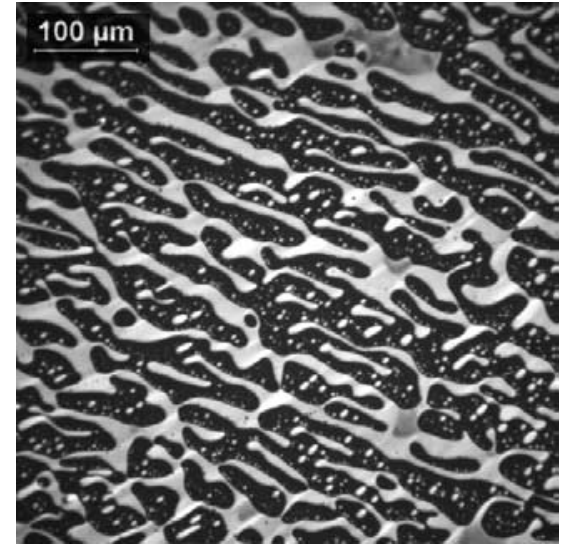

Fig. 1. Sample texture: $100 \times$ magnified bitumen with $6 \%$ Elvaloy ${ }^{\circledR} 3427$.

\section{Fluorescence microscopy}

In describing the microstructure interacting between bitumen and polymer, the term "morphology" is often used [8]. Fluorescence microscopy is used to investigate the morphology of the EBA, EVA, and SBS PMBs by determining the state of dispersion of the polymer within the base bitumen as well as to characterize the nature of the continuous and discontinuous phase. Fluorescence microscopy is a valuable tool for studying the phase morphology of PMB, as it allows the observation of the homogeneity and the structure in the raw state [9].

Fluorescence microscopy is based on the principle that polymers swell due to the absorption of some of the constituents of the base bitumen. Due to the fluorescence effect the bitumen rich phase appears dark or black, whereas the polymer rich phase appears light [10] (e.g. Fig. 1).

Samples of each PMB were prepared (for imaging purposes) by using a standard sample preparation method that involves a heating and homogenizing procedure a sample cooling regime as well as a surface preparation procedure over thin films of the samples [11].

PMB samples were examined at room temperature under a Leica DM EP microscope with fluorescent light (generated from a high pressure Xenon lamp) at magnification levels of $400 \times, 100 \times$, and $40 \times$. Images were then taken by a 7.2 Mp Leica DFC 320 color camera fitted in line with the optic axis of the microscope by means of an attachment to the trinocular observation head. The camera digitizes the image and stores the data as an image file in the hard drive of the workstation.

\section{Texture representation using Gabor filters}

Textural features of images are usually extracted by applying a series of mathematical transformations and measurements that measure physical quantities. Typically, these quantities are related to image deviations in different scales and orientations. One of the most common techniques for extracting textural features is texture analysis using Gabor filters [12]. After the application of Gabor filters, filter responses corresponding to different scales and orientations can be used as textural features that characterize physical properties of image data. Gabor filters are widely used in many different applications of texture analysis such as con- tent based image retrieval [13-16], remote sensing [17, 18], fault detection $[19,20]$, biometric identification [2127], medical image analysis [28, 29], object recognition [30, 31], optical text processing [32-34], etc.

Gabor filters can be implemented using a directional and scaled set of Gaussian filters. A bivariate Gaussian function can be represented as:

$g_{\sigma}(x, y)=\frac{1}{2 \pi \sigma_{x} \sigma_{y}} e^{-\frac{1}{2}\left(\frac{x^{2}}{\sigma_{x}^{2}}+\frac{y^{2}}{\sigma_{y}^{2}}\right)}$

A two dimensional Gabor function can be obtained by multiplying a Gaussian function by a complex exponential:

$G(x, y)=g_{\sigma}(x, y) e^{-2 \pi j W x}$

Where $W$ is the modulation frequency and $\left(\sigma_{x}, \sigma_{y}\right)$ are the scale variables that determine the size of the spread in Gaussian functions.

The Fourier transform of $G(x, y)$ becomes:

$G(u, v)=e^{-\frac{1}{2}\left[\frac{(u-W)^{2}}{\sigma_{u}^{2}}+\frac{v^{2}}{\sigma_{v}^{2}}\right]}$

Here, it can be observed that the scale variables in the spatial and frequency domain are related to each other by: $\sigma_{u}=\frac{1}{2} \pi \sigma_{x}, \sigma_{v}=\frac{1}{2} \pi \sigma_{y}$.

A set of Gabor filters can be derived using Gaussian filters in different scales and orientations as introduced in [13, 35]. The main purpose of this operation is to span the frequency domain uniformly. The filter variables are found as:

$$
\begin{aligned}
& a=\left(\frac{U_{\mathrm{h}}}{U_{1}}\right)^{\frac{1}{S-1}}, \\
& \sigma_{u}=\frac{(a-1) U_{\mathrm{h}}}{(a+1) \sqrt{2 \ln 2}}, \quad \sigma_{v}=\tan \left(\frac{\pi}{2 k}\right) \sqrt{\frac{U_{\mathrm{h}}^{2}}{2 \ln 2}-\sigma_{u}^{2}}
\end{aligned}
$$

Where: $U_{1}, U_{\mathrm{h}}(=W)$ are the center frequencies of Gabor filters with lowest and highest frequency bands respectively. The Gabor filters with $S$ different scales and $K$ different orientations are found as:

$$
\begin{aligned}
& G_{m n}(x, y)=a^{-m} G(\bar{x}, \bar{y}) \\
& \bar{x}=a^{-m}(\cos \theta+y \sin \theta), \quad \bar{y}=a^{-m}(-x \sin \theta+y \cos \theta) \\
& m=0,1, \ldots, S-1 \\
& \theta=\frac{n \pi}{K}, \quad n=0,1, . ., K-1
\end{aligned}
$$

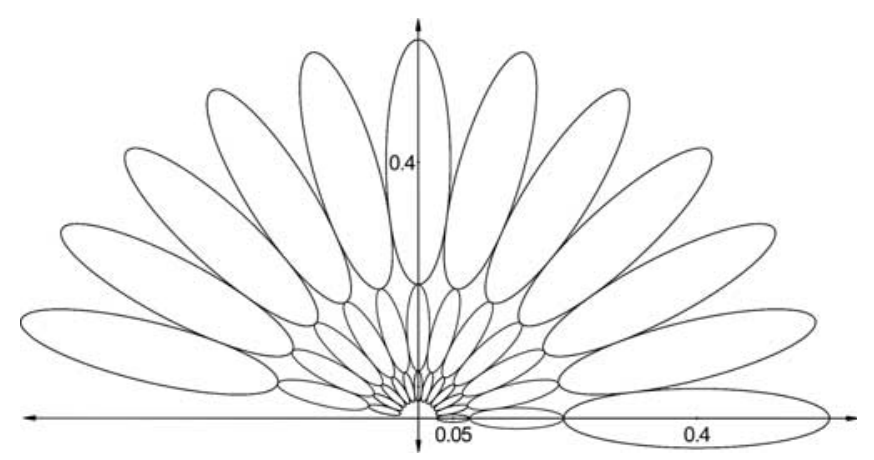

Fig. 2. Isocontours of Gabor filter responses at half peak values in spatial frequency space for 6 orientations and 4 scales [25]. $U_{1}=0.05, U_{\mathrm{h}}=0.4$.

Int. J. Mat. Res. (formerly Z. Metallkd.) 102 (2011) 5 

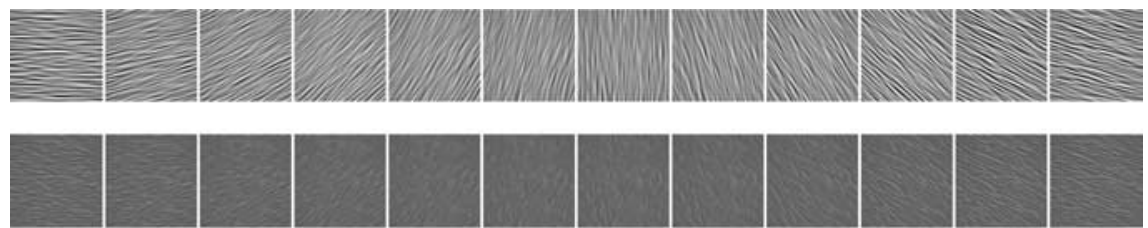

Fig. 3. Gabor filter responses for 12 different orientations (columns) and 3 different scales (rows).

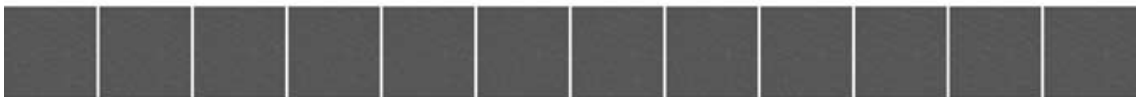

The Gabor filters described above uniformly cover the spatial frequency space as illustrated in Fig. 2.

Gabor filters can be applied to an $\mathrm{N} \times \mathrm{M}$ image $I(x, y)$ by:

$I_{m n}(x, y)=\sum_{p} \sum_{q} I(x-p, y-q) G_{m n}^{*}(x, y)$

where "*” is used for the complex conjugate. This Gabor transformation corresponds to scale $m$ and orientation $n$. This is illustrated in Fig. 3 where Gabor filters are applied for 3 scales and 12 orientations on the sample image. Magnitudes of the complex images are displayed.

Average values and deviation values of $\mathrm{S} \times \mathrm{K}$ (i.e. number of scales $\times$ number of orientations) images are used as the textural features $[13,35]$ :

$\mu_{m n}=\frac{\sum_{x} \sum_{y}\left|G_{m n}(x, y)\right|}{M N}$

$\sigma_{m n}=\sqrt{\frac{\sum_{x} \sum_{y}\left(\left|G_{m n}(x, y)\right|-\mu_{m n}\right)^{2}}{M N}}$

A feature vector can be formed by cascading mean and deviation values for all $m$ and $n$ :

$\boldsymbol{F}=\left\{\mu_{00}, \sigma_{00}, \mu_{10}, \sigma_{10}, \ldots, \mu_{(S-1) 0}\right.$,

$$
\left.\sigma_{(S-1) 0}, \ldots, \mu_{(S-1)(K-1)}, \sigma_{(S-1)(K-1)}\right\}
$$

The distance between two feature vectors $\boldsymbol{F}^{(i)}$ and $\boldsymbol{F}^{(j)}$ extracted from two images can be defined as:

$d(i, j)=\sqrt{\sum_{m} \sum_{n}\left(\frac{\mu_{m n}^{(i)}-\mu_{m n}^{(j)}}{\sigma_{\mu(m, n)}}\right)^{2}+\left(\frac{\sigma_{m n}^{(i)}-\sigma_{m n}^{(j)}}{\sigma_{\sigma(m, n)}}\right)^{2}}$

$m=0,1, \ldots, S-1 n=0,1, \ldots, K-1$

The distance metric used here is the Euclidian distance between the terms which are normalized by standard deviation. The order of feature values in the feature vectors is directly related to the orientation of the textures. As depicted in Fig. 3, it can be seen that the dominant texture orientation causes the filter responses to have a higher degree of variations for the Gabor filters steered in that particular direction. Texture analysis applications should be able to identify textures correctly even if they are rotated in an arbitrary direction. Several approaches have been proposed to make the texture analysis rotation invariant [35-40]. These methods generally depend on mapping feature points to a different space with rotation invariance properties (by Fourier Transform, etc.) or reorganizing feature vectors by rotational shift operations. In this study, differ- ent approaches are adopted for rotational invariance of Gabor features. One of these approaches is based on finding the most dominant orientation and reorganizing the feature values by a rotational shift such that the peak value is placed at the leftmost position [35]. Another approach is based on calculating the distance between two feature vectors by circularly shifting one of the vectors and using the shift position that gives the minimum distance between the two vectors.

After different types of bitumen (i.e. base and modified by EBA, EVA, and SBS) images were captured using a microscope-mounted digital camera, three different approaches (named A, B and C) were tested on the images to see how well Gabor features represent image textures. The $\mathrm{A}, \mathrm{B}$ and $\mathrm{C}$ methods can be summarized as:

Method A: Direct use of Gabor features (with no effort to satisfy rotation invariance).

Method B: The peak value corresponding to the orientation with highest energy is computed and the feature vector is circularly shifted until the peak value is placed at the leftmost position.

Method C: One of the feature vectors were circularly shifted for all possible cases and its distance to the second feature is calculated for each of these cases and the minimum distance value is recorded.

\section{K-nearest neighbor (K-NN) classification}

The K-NN classifier [41] is one of the classical techniques that allow classification of samples in a feature space merely based on their distances to training samples. For each query sample, the class that contains the most of the nearest $k$ samples is assigned as the class for the query sample. The choice of $k$ is limited by 1 and the number of samples in each training class. A choice of small $k$ may lead to complicated decision boundaries that may be negatively affected by outlier samples. A large $k$ introduces smooth decision regions at the expense of increased computational burden and lost local selectivity. In this paper performance results are computed for five values of $k$ (from 1 to 5 ) and the average values are reported. The K-NN classifier is tested on the Gabor features of modified bitumen using the leave-one-out (LOO) cross validation technique.

For each query sample with a known class, the rest of the samples are used as the training set. The rate of query samples correctly classified by K-NN is recorded as the success rate for the query class. The samples that are assigned to wrong classes may be used to create a confusion matrix (as in Table 8) which represents the distribution of classification results. 


\section{Experimental results}

Texture analysis on microscopic images of modified bitumen provides us with a framework to evaluate several aspects of materials without the need of chemical and

(a)

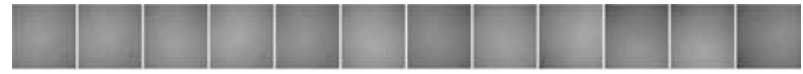

(b)

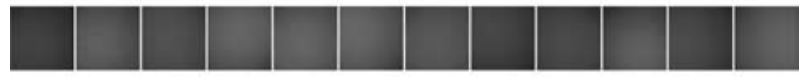

(c)

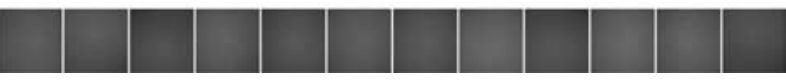

Fig. 4. Base bitumen images: (a) $400 \times$ (b) $100 \times$ (c) $40 \times$ magnification.

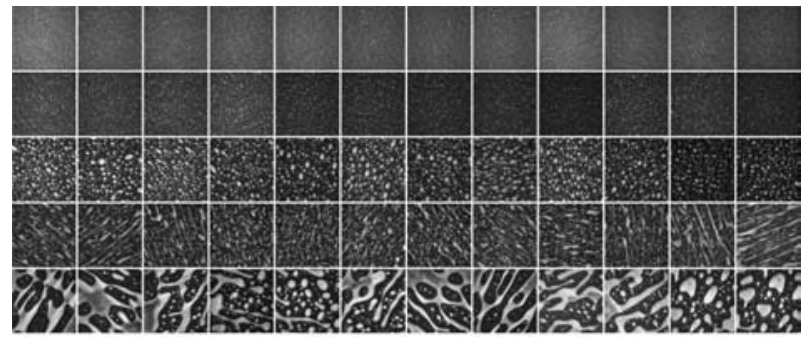

(b)

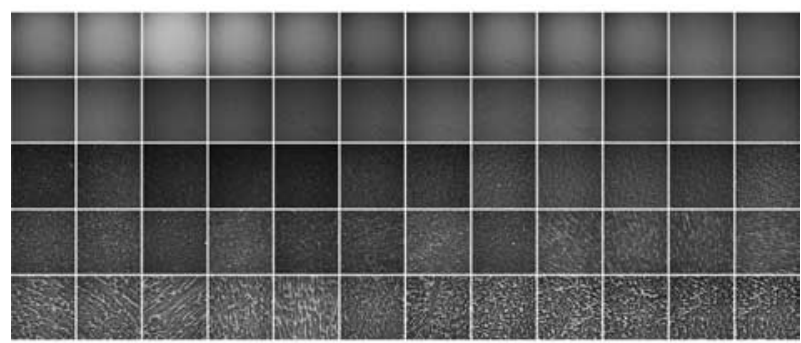

(c)

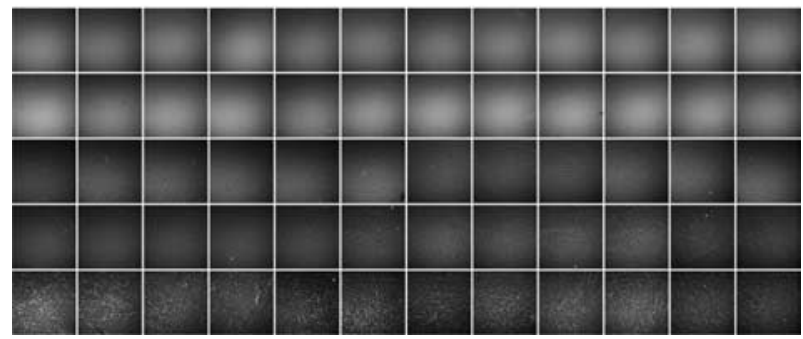

Fig. 5. Images of bitumen with Elvaloy ${ }^{\circledR} 3427$ in (a) $400 \times$ (b) $100 \times$ (c) $40 \times$ magnification. In each row, samples contain different percentage of polymers $(3-7 \%)$. mechanical tests. A human observer can easily distinguish physical characteristics of modified bitumen images (Figs. 4-9). In order to perform the operation automatically on a computer, the key features of the images that are common in the same class of images, but are not typically shared in different classes should be identified.

Twelve images were captured for each magnification factor; polymer type, and different polymer contents. A set of 36 Gabor features were computed as described in Eq. (8). These features correspond to responses of filters as illustrated in Fig. 1 and Fig. 3. In order to test how well textural features represent key characteristics of bitumen images, 3 different tests were performed:

1. This test is performed to determine how well the images of PMB with different contents (or mixture rates) of poly-

(a)

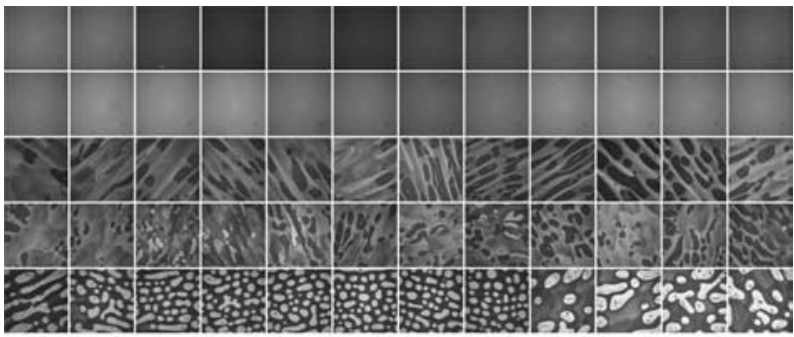

(b)

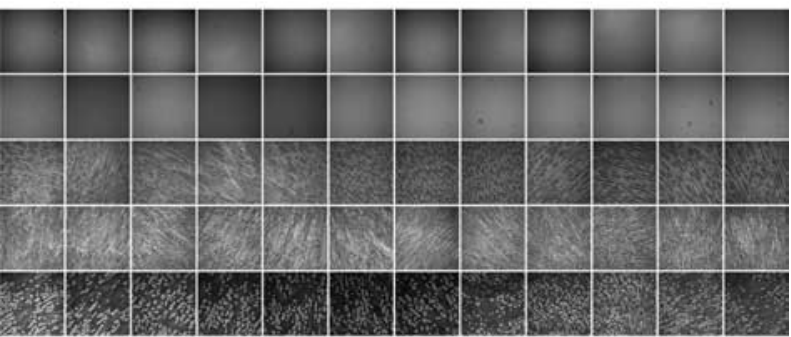

(c)

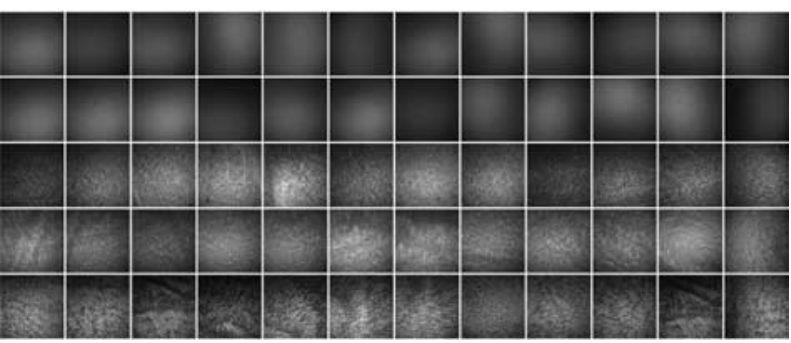

Fig. 6. Images of bitumen with Evatene ${ }^{\circledR} 2805$ in (a) $400 \times$ (b) $100 \times$ (c) $40 \times$ magnification. In each row, samples contain different percentage of polymers $(2-6 \%)$.

Table 1. The percentage success rate of A, B and C measures on 3-7 Elvaloy ${ }^{\circledR} 3427$ modified bitumen images with $400 \times, 100 \times, 40 \times$ magnification.

\begin{tabular}{|c|c|c|c|c|c|c|c|c|c|c|}
\hline \multirow[t]{2}{*}{ Polymer type } & \multirow{2}{*}{$\begin{array}{c}\text { Content } \\
(\%)\end{array}$} & \multicolumn{3}{|c|}{$400 \times$} & \multicolumn{3}{|c|}{$100 \times$} & \multicolumn{3}{|c|}{$40 \times$} \\
\hline & & $\begin{array}{c}\mathrm{A} \\
(\%)\end{array}$ & $\begin{array}{c}\mathrm{B} \\
(\%)\end{array}$ & $\begin{array}{c}\mathrm{C} \\
(\%)\end{array}$ & $\begin{array}{c}\mathrm{A} \\
(\%)\end{array}$ & $\begin{array}{c}\text { B } \\
(\%)\end{array}$ & $\begin{array}{c}\mathrm{C} \\
(\%)\end{array}$ & $\begin{array}{c}\mathrm{A} \\
(\%)\end{array}$ & $\begin{array}{c}\mathrm{B} \\
(\%)\end{array}$ & $\begin{array}{c}\mathrm{C} \\
(\%)\end{array}$ \\
\hline Elvaloy ${ }^{\circledR} 3427$ & $\begin{array}{c}2 \\
3 \\
4 \\
5 \\
6 \\
\text { Average }\end{array}$ & $\begin{array}{c}100 \\
100 \\
98.33 \\
73.33 \\
100 \\
94.33\end{array}$ & $\begin{array}{c}100 \\
100 \\
88.33 \\
100 \\
98.33 \\
97.33\end{array}$ & $\begin{array}{c}100 \\
100 \\
91.67 \\
100 \\
100 \\
98.33\end{array}$ & $\begin{array}{c}98.33 \\
93.33 \\
95.00 \\
88.33 \\
100 \\
95.00\end{array}$ & $\begin{array}{c}98.33 \\
96.67 \\
93.33 \\
83.33 \\
100 \\
94.33\end{array}$ & $\begin{array}{c}98.33 \\
98.33 \\
95.00 \\
90.00 \\
100 \\
96.33\end{array}$ & $\begin{array}{c}88.33 \\
91.67 \\
90.00 \\
91.67 \\
100 \\
92.33\end{array}$ & $\begin{array}{c}88.33 \\
91.67 \\
88.33 \\
100 \\
100 \\
93.67\end{array}$ & $\begin{array}{c}88.33 \\
91.67 \\
90.00 \\
100 \\
100 \\
94.00\end{array}$ \\
\hline
\end{tabular}


mers can be identified using textural features. PMB images that belong to a group (i.e. Elvaloy ${ }^{\circledR} 3427$, Evatene $^{\circledR} 2805$, Elvaloy ${ }^{\circledR} 4170$, Kraton $^{\circledR}$ D1101, Soltene ${ }^{\circledR}$ $6302)$ with all available mixture rates at a specific magnification scale $(400 \times, 100 \times$, and $40 \times)$ are used in a query. For instance, 60 images presented in Fig. $5 b$ are used as training set for the Elvaloy ${ }^{\circledR} 3427100 \times$ query. The resulting sequence is sorted with respect to similarity (i.e. small distance) with respect to the query sample. The average $\mathrm{K}-\mathrm{NN}$ score of 12 queries is recorded as the success rate corresponding to the class (i.e. content or mixture rate). Performance results of each method on different magnification scales (Figs. 4-9) can be seen in Tables 1-5. It can be seen that for the most polymer types, when a proper magnification scale and method are selected, the query results return images of the same polymer content with significant success.

2. In this test the query is performed within the whole data set of 300 images. The average K-NN results for 12 query samples belonging to the class is used to find the success rate for a particular class (i.e. a specific mixture rate of a specific polymer type).

The results of this test are presented in Table 6. It can be seen that it is possible to identify an image of a specific polymer content of a specific polymer type with significant success rates when proper methods and magnification scales are selected.

3. The final test is performed to see whether it is possible to determine the type of polymer using a query of a bitumen image with a known magnification and an arbitrary mixture rate. All images are labeled by main groups (Base, EBA, EVA, SBS) and a query is done on all images. K-NN results for query samples belonging to the class label is used to find the success rate for a particular class (polymer type).
Table 7 presents the results of the third test. It can be seen that textural features represent characteristics of the polymer modification when proper magnification scales and distance metrics are selected.

Table 8 shows the confusion matrices for the selected methods that are marked in Table 7. It provides information on the wrongfully selected classes for each case.

(a)

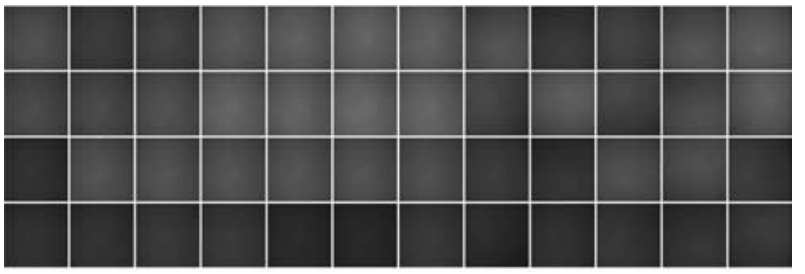

(b)

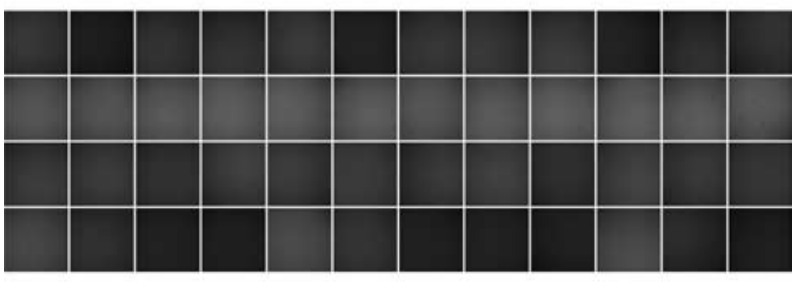

(c)

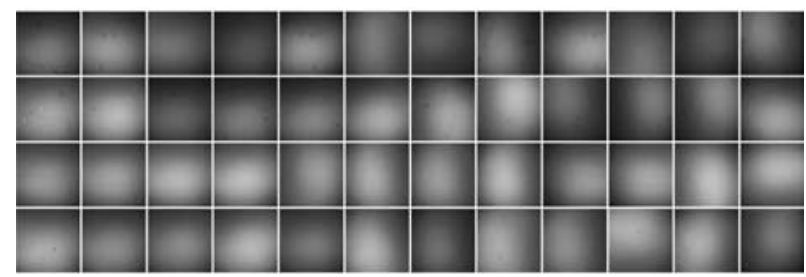

Fig. 7. Images of bitumen with Elvaloy ${ }^{\circledR} 4170$ in (a) $400 \times$ (b) $100 \times$ (c) $40 \times$ magnification. In each row, samples contain different percentage of polymers $(0.5 \%, 1 \%, 1.5 \%, 1.75 \%)$.

Table 2. The percentage success rate of A, B and C measures on 2-6\% Evatene ${ }^{\circledR} 2805$ modified bitumen images with $400 \times, 100 \times$, $40 \times$, magnification.

\begin{tabular}{|c|c|c|c|c|c|c|c|c|c|c|}
\hline \multirow[t]{2}{*}{ Polymer type } & \multirow{2}{*}{$\begin{array}{c}\text { Content } \\
(\%)\end{array}$} & \multicolumn{3}{|c|}{$400 \times$} & \multicolumn{3}{|c|}{$100 \times$} & \multicolumn{3}{|c|}{$40 \times$} \\
\hline & & $\begin{array}{c}\mathrm{A} \\
(\%)\end{array}$ & $\begin{array}{c}\mathrm{B} \\
(\%)\end{array}$ & $\underset{(\%)}{\mathrm{C}}$ & $\begin{array}{c}\mathrm{A} \\
(\%)\end{array}$ & $\begin{array}{c}\text { B } \\
(\%)\end{array}$ & $\begin{array}{c}\mathrm{C} \\
(\%)\end{array}$ & $\begin{array}{c}\mathrm{A} \\
(\%)\end{array}$ & $\begin{array}{c}\text { B } \\
(\%)\end{array}$ & $\begin{array}{c}\mathrm{C} \\
(\%)\end{array}$ \\
\hline Evatene $^{\circledR} 2805$ & $\begin{array}{c}3 \\
4 \\
5 \\
6 \\
7 \\
\text { Average }\end{array}$ & $\begin{array}{c}83.33 \\
91.67 \\
48.33 \\
93.33 \\
100 \\
83.33\end{array}$ & $\begin{array}{c}83.33 \\
91.67 \\
75.00 \\
91.67 \\
100 \\
88.33\end{array}$ & $\begin{array}{c}83.33 \\
91.67 \\
75.00 \\
91.67 \\
100 \\
88.33\end{array}$ & $\begin{array}{c}90.00 \\
86.67 \\
78.33 \\
100 \\
100 \\
91.00\end{array}$ & $\begin{array}{c}90.00 \\
86.67 \\
91.67 \\
100 \\
100 \\
93.67\end{array}$ & $\begin{array}{c}86.67 \\
90.00 \\
91.67 \\
100 \\
100 \\
93.67\end{array}$ & $\begin{array}{c}91.67 \\
81.67 \\
61.67 \\
91.67 \\
100 \\
85.33\end{array}$ & $\begin{array}{c}91.67 \\
81.67 \\
80.00 \\
91.67 \\
100 \\
89.00\end{array}$ & $\begin{array}{c}91.67 \\
81.67 \\
85.00 \\
81.67 \\
100 \\
88.00\end{array}$ \\
\hline
\end{tabular}

Table 3. The percentage success rate of $\mathrm{A}, \mathrm{B}$ and $\mathrm{C}$ measures on $0.5,1,1.5$, and 1.75 Elvaloy ${ }^{\circledR} 4170$ modified bitumen images with $400 \times, 100 \times, 40 \times$ magnification.

\begin{tabular}{|c|c|c|c|c|c|c|c|c|c|c|}
\hline \multirow[t]{2}{*}{ Polymer type } & \multirow{2}{*}{$\begin{array}{l}\text { Content } \\
(\%)\end{array}$} & \multicolumn{3}{|c|}{$400 \times$} & \multicolumn{3}{|c|}{$100 \times$} & \multicolumn{3}{|c|}{$40 \times$} \\
\hline & & $\begin{array}{c}\mathrm{A} \\
(\%)\end{array}$ & $\begin{array}{c}\text { B } \\
(\%)\end{array}$ & $\begin{array}{c}\mathrm{C} \\
(\%)\end{array}$ & $\begin{array}{c}\mathrm{A} \\
(\%)\end{array}$ & $\begin{array}{c}\text { B } \\
(\%)\end{array}$ & $\begin{array}{c}\mathrm{C} \\
(\%)\end{array}$ & $\begin{array}{c}\mathrm{A} \\
(\%)\end{array}$ & $\begin{array}{c}\mathrm{B} \\
(\%)\end{array}$ & $\begin{array}{c}\mathrm{C} \\
(\%)\end{array}$ \\
\hline Elvaloy ${ }^{\circledR} 4170$ & $\begin{array}{c}0.5 \\
1 \\
1.5 \\
1.75 \\
\text { Average }\end{array}$ & $\begin{array}{l}16.67 \\
81.67 \\
76.67 \\
98.33 \\
68.33\end{array}$ & $\begin{array}{l}16.67 \\
81.67 \\
76.67 \\
98.33 \\
68.33\end{array}$ & $\begin{array}{l}16.67 \\
81.67 \\
76.67 \\
98.33 \\
68.33\end{array}$ & $\begin{array}{c}18.33 \\
100 \\
73.33 \\
76.67 \\
67.08\end{array}$ & $\begin{array}{c}18.33 \\
100 \\
73.33 \\
76.67 \\
67.08\end{array}$ & $\begin{array}{c}18.33 \\
100 \\
73.33 \\
76.67 \\
67.08\end{array}$ & $\begin{array}{r}76.67 \\
8.33 \\
58.33 \\
68.33 \\
52.92\end{array}$ & $\begin{array}{r}76.67 \\
8.33 \\
58.33 \\
68.33 \\
52.92\end{array}$ & $\begin{array}{r}75.00 \\
8.33 \\
36.67 \\
45.00 \\
41.25\end{array}$ \\
\hline
\end{tabular}


The tests described above confirm that queries for samples selected from different classes return samples within the same class for most of the cases. It can be seen that different

(a)

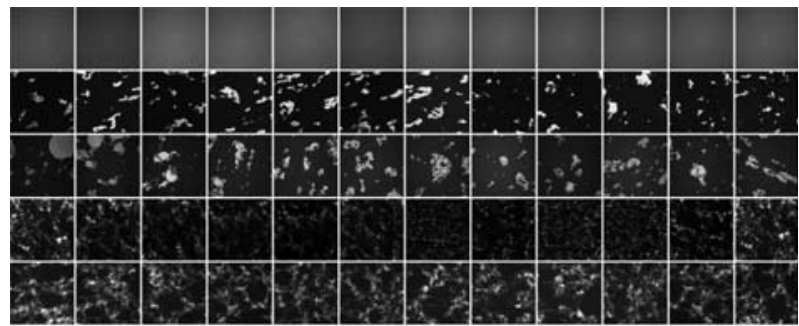

(b)

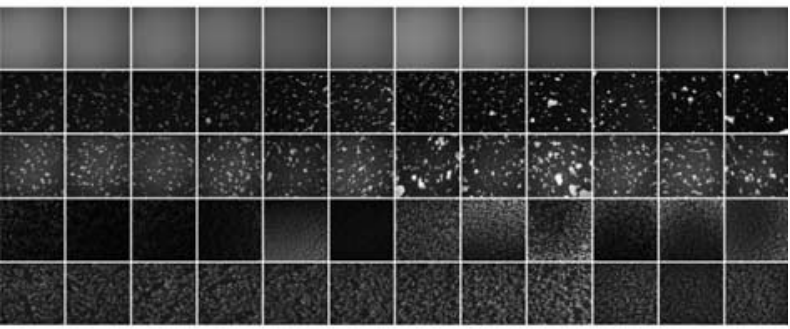

(c)

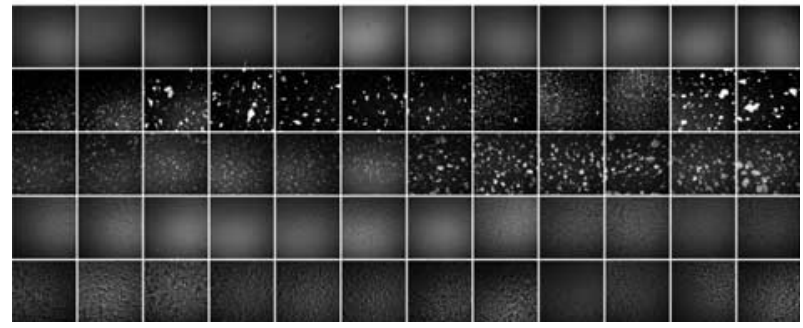

Fig. 8. Images of bitumen with $\operatorname{Kraton}^{\circledR}$ D1101 in (a) $400 \times$ (b) $100 \times$ (c) $40 \times$ magnification. In each row, samples contain different percentage of polymers $(2-6 \%)$. methods (i.e. A, B and $\mathrm{C}$ here), may perform with different success rates on the data and performance rates also differ with respect to different magnification scales. For instance,

(a)

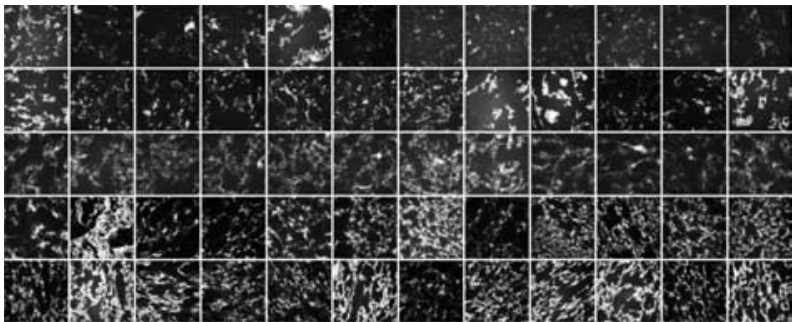

(b)

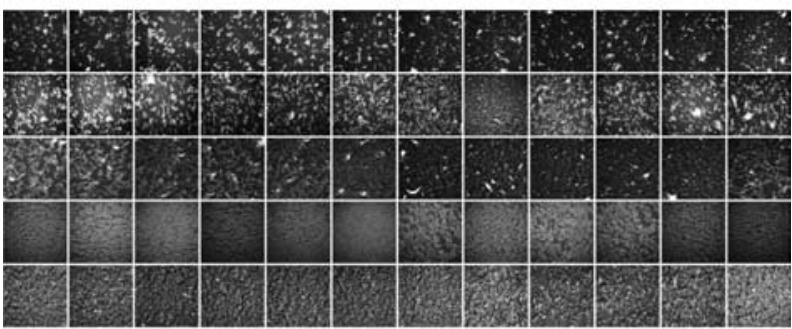

(c)

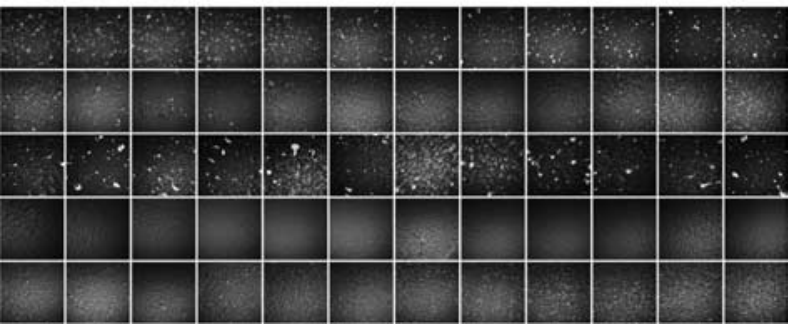

Fig. 9. Images of bitumen with Soltene ${ }^{\circledR} 6302$ in (a) $400 \times$ (b) $100 \times$ (c) $40 \times$ magnification. In each row, samples contain different percentage of polymers $(2-6 \%)$.

Table 4. The percentage success rate of A, B and C measures on $2-6 \%$ Kraton ${ }^{\circledR}$ D1101 modified bitumen images with $400 \times, 100 \times$, $40 \times$ magnification.

\begin{tabular}{|c|c|c|c|c|c|c|c|c|c|c|}
\hline \multirow[t]{2}{*}{ Polymer type } & \multirow{2}{*}{$\begin{array}{c}\text { Content } \\
(\%)\end{array}$} & \multicolumn{3}{|c|}{$400 \times$} & \multicolumn{3}{|c|}{$100 \times$} & \multicolumn{3}{|c|}{$40 \times$} \\
\hline & & $\begin{array}{c}\mathrm{A} \\
(\%)\end{array}$ & $\begin{array}{c}\mathrm{B} \\
(\%)\end{array}$ & $\begin{array}{c}\mathrm{C} \\
(\%)\end{array}$ & $\begin{array}{c}\mathrm{A} \\
(\%)\end{array}$ & $\begin{array}{c}\mathrm{B} \\
(\%)\end{array}$ & $\begin{array}{c}\mathrm{C} \\
(\%)\end{array}$ & $\begin{array}{c}\mathrm{A} \\
(\%)\end{array}$ & $\begin{array}{c}\mathrm{B} \\
(\%)\end{array}$ & $\begin{array}{c}\mathrm{C} \\
(\%)\end{array}$ \\
\hline Kraton $^{\circledR}$ D1101 & $\begin{array}{c}2 \\
3 \\
4 \\
5 \\
6 \\
\text { Average }\end{array}$ & $\begin{array}{c}100 \\
90.00 \\
40.00 \\
86.67 \\
85.00 \\
80.33\end{array}$ & $\begin{array}{c}100 \\
91.67 \\
15.00 \\
78.33 \\
83.33 \\
73.67\end{array}$ & $\begin{array}{c}100 \\
91.67 \\
15.00 \\
85.00 \\
85.00 \\
75.33\end{array}$ & $\begin{array}{c}100 \\
100 \\
80.00 \\
55.00 \\
93.33 \\
85.67\end{array}$ & $\begin{array}{c}100 \\
100 \\
78.33 \\
51.67 \\
90.00 \\
84.00\end{array}$ & $\begin{array}{c}100 \\
100 \\
85.00 \\
46.67 \\
96.67 \\
85.67\end{array}$ & $\begin{array}{l}81.67 \\
96.67 \\
61.67 \\
88.33 \\
95.00 \\
84.67\end{array}$ & $\begin{array}{c}81.67 \\
100 \\
43.33 \\
90.00 \\
86.67 \\
80.33\end{array}$ & $\begin{array}{l}81.67 \\
96.67 \\
78.33 \\
91.67 \\
88.33 \\
87.33\end{array}$ \\
\hline
\end{tabular}

Table 5. The percentage success rate of A, B and C measures on $2-6 \%$ Soltene ${ }^{\circledR} 6302$ modified bitumen images with $400 \times, 100 \times, 40 \times$ magnification.

\begin{tabular}{|c|c|c|c|c|c|c|c|c|c|c|}
\hline \multirow[t]{2}{*}{ Polymer type } & \multirow{2}{*}{$\begin{array}{c}\text { Content } \\
(\%)\end{array}$} & \multicolumn{3}{|c|}{$400 \times$} & \multicolumn{3}{|c|}{$100 \times$} & \multicolumn{3}{|c|}{$40 \times$} \\
\hline & & $\begin{array}{c}\mathrm{A} \\
(\%)\end{array}$ & $\begin{array}{c}\text { B } \\
(\%)\end{array}$ & $\begin{array}{c}\mathrm{C} \\
(\%)\end{array}$ & $\begin{array}{c}\mathrm{A} \\
(\%)\end{array}$ & $\begin{array}{c}\mathrm{B} \\
(\%)\end{array}$ & $\begin{array}{c}\mathrm{C} \\
(\%)\end{array}$ & $\begin{array}{c}\mathrm{A} \\
(\%)\end{array}$ & $\begin{array}{c}\mathrm{B} \\
(\%)\end{array}$ & $\begin{array}{c}\mathrm{C} \\
(\%)\end{array}$ \\
\hline Soltene 6302 & $\begin{array}{c}2 \\
3 \\
4 \\
5 \\
6 \\
\text { Average }\end{array}$ & $\begin{array}{l}55.00 \\
61.67 \\
91.67 \\
31.67 \\
45.00 \\
57.00\end{array}$ & $\begin{array}{l}53.33 \\
63.33 \\
91.67 \\
16.67 \\
88.33 \\
62.67\end{array}$ & $\begin{array}{l}55.00 \\
63.33 \\
91.67 \\
41.67 \\
81.67 \\
66.67\end{array}$ & $\begin{array}{c}96.67 \\
88.33 \\
80.00 \\
100 \\
95.00 \\
92.00\end{array}$ & $\begin{array}{c}83.33 \\
86.67 \\
80.00 \\
100 \\
93.33 \\
88.67\end{array}$ & $\begin{array}{c}90.00 \\
88.33 \\
83.33 \\
100 \\
96.67 \\
91.67\end{array}$ & $\begin{array}{c}100 \\
88.33 \\
80.00 \\
61.67 \\
75.00 \\
81.00\end{array}$ & $\begin{array}{c}100 \\
86.67 \\
90.00 \\
68.33 \\
73.33 \\
83.67\end{array}$ & $\begin{array}{l}95.00 \\
86.67 \\
86.67 \\
38.33 \\
66.67 \\
74.67\end{array}$ \\
\hline
\end{tabular}


Ş. Gümüştekin et al.: Texture analysis of polymer modified bitumen images

Table 6. The percentage success rate of A, B and C measures on Base bitumen and all PMB images with $400 \times, 100 \times, 40 \times$ magnification.

\begin{tabular}{|c|c|c|c|c|c|c|c|c|c|c|}
\hline \multirow[t]{2}{*}{ Polymer type } & \multirow[t]{2}{*}{ Content } & \multicolumn{3}{|c|}{$400 \times$} & \multicolumn{3}{|c|}{$100 \times$} & \multicolumn{3}{|c|}{$40 \times$} \\
\hline & & $\begin{array}{c}\mathrm{A} \\
(\%)\end{array}$ & $\begin{array}{c}\mathrm{B} \\
(\%)\end{array}$ & $\begin{array}{c}\mathrm{C} \\
(\%)\end{array}$ & $\begin{array}{c}\mathrm{A} \\
(\%)\end{array}$ & $\begin{array}{c}\mathrm{B} \\
(\%)\end{array}$ & $\begin{array}{c}\mathrm{C} \\
(\%)\end{array}$ & $\begin{array}{c}\mathrm{A} \\
(\%)\end{array}$ & $\begin{array}{c}\mathrm{B} \\
(\%)\end{array}$ & $\begin{array}{c}\mathrm{C} \\
(\%)\end{array}$ \\
\hline$-($ Base $)$ & 0 & 86.67 & 86.67 & 86.67 & 51.67 & 51.67 & 51.67 & 100 & 100 & 100 \\
\hline Elvaloy ${ }^{\circledR} 3427$ & $\begin{array}{l}2 \\
3 \\
4 \\
5 \\
6\end{array}$ & $\begin{array}{l}90.00 \\
98.33 \\
81.67 \\
76.67 \\
95.00\end{array}$ & $\begin{array}{c}88.33 \\
100 \\
71.67 \\
100 \\
90.00\end{array}$ & $\begin{array}{c}90.00 \\
88.33 \\
75.00 \\
100 \\
95.00\end{array}$ & $\begin{array}{l}75.00 \\
88.33 \\
56.67 \\
83.33 \\
88.33\end{array}$ & $\begin{array}{c}75.00 \\
96.67 \\
81.67 \\
76.67 \\
100\end{array}$ & $\begin{array}{l}75.00 \\
98.33 \\
95.00 \\
83.33 \\
98.33\end{array}$ & $\begin{array}{l}70.00 \\
90.00 \\
90.00 \\
91.67 \\
55.00\end{array}$ & $\begin{array}{c}70.00 \\
90.00 \\
88.33 \\
100 \\
73.33\end{array}$ & $\begin{array}{c}75.00 \\
90.00 \\
90.00 \\
100 \\
73.33\end{array}$ \\
\hline Evatene $^{\circledR} 2805$ & $\begin{array}{l}3 \\
4 \\
5 \\
6 \\
7\end{array}$ & $\begin{array}{l}18.33 \\
88.33 \\
30.00 \\
88.33 \\
96.67\end{array}$ & $\begin{array}{l}18.33 \\
88.33 \\
58.33 \\
83.33 \\
91.67\end{array}$ & $\begin{array}{c}18.33 \\
88.33 \\
66.67 \\
86.67 \\
100\end{array}$ & $\begin{array}{c}80.00 \\
20.00 \\
75.00 \\
100 \\
66.67\end{array}$ & $\begin{array}{c}78.33 \\
20.00 \\
91.67 \\
100 \\
60.00\end{array}$ & $\begin{array}{c}70.00 \\
23.33 \\
91.67 \\
100 \\
68.33\end{array}$ & $\begin{array}{l}43.33 \\
58.33 \\
68.33 \\
85.00 \\
91.67\end{array}$ & $\begin{array}{l}40.00 \\
58.33 \\
81.67 \\
85.00 \\
93.33\end{array}$ & $\begin{array}{l}41.67 \\
58.33 \\
85.00 \\
71.67 \\
96.67\end{array}$ \\
\hline Elvaloy ${ }^{\circledR} 4170$ & $\begin{array}{c}0.5 \\
1 \\
1.5 \\
1.75\end{array}$ & $\begin{array}{l}18.33 \\
60.00 \\
71.67 \\
98.33\end{array}$ & $\begin{array}{l}18.33 \\
60.00 \\
71.67 \\
98.33\end{array}$ & $\begin{array}{l}18.33 \\
60.00 \\
71.67 \\
98.33\end{array}$ & $\begin{array}{l}18.33 \\
96.67 \\
73.33 \\
65.00\end{array}$ & $\begin{array}{l}18.33 \\
96.67 \\
73.33 \\
65.00\end{array}$ & $\begin{array}{l}18.33 \\
96.67 \\
73.33 \\
65.00\end{array}$ & $\begin{array}{l}48.33 \\
10.00 \\
20.00 \\
30.00\end{array}$ & $\begin{array}{l}48.33 \\
10.00 \\
20.00 \\
30.00\end{array}$ & $\begin{array}{l}36.67 \\
11.67 \\
15.00 \\
16.67\end{array}$ \\
\hline Kraton $^{\circledR}$ D1101 & $\begin{array}{l}2 \\
3 \\
4 \\
5 \\
6\end{array}$ & $\begin{array}{l}26.67 \\
78.33 \\
41.67 \\
81.67 \\
81.67\end{array}$ & $\begin{array}{l}25.00 \\
78.33 \\
15.00 \\
83.33 \\
81.67\end{array}$ & $\begin{array}{r}26.67 \\
83.33 \\
6.67 \\
83.33 \\
83.33\end{array}$ & $\begin{array}{c}58.33 \\
100 \\
50.00 \\
43.33 \\
75.00\end{array}$ & $\begin{array}{c}58.33 \\
100 \\
51.67 \\
41.67 \\
75.00\end{array}$ & $\begin{array}{c}58.33 \\
100 \\
33.33 \\
30.00 \\
81.67\end{array}$ & $\begin{array}{l}21.67 \\
95.00 \\
48.33 \\
45.00 \\
70.00\end{array}$ & $\begin{array}{l}21.67 \\
98.33 \\
45.00 \\
41.67 \\
55.00\end{array}$ & $\begin{array}{c}8.33 \\
93.33 \\
66.67 \\
43.33 \\
78.33\end{array}$ \\
\hline Soltene ${ }^{\circledR} 6302$ & $\begin{array}{c}2 \\
3 \\
4 \\
5 \\
6 \\
\text { Average }\end{array}$ & $\begin{array}{l}50.00 \\
43.33 \\
90.00 \\
45.00 \\
60.00 \\
67.87\end{array}$ & $\begin{array}{l}51.67 \\
41.67 \\
90.00 \\
35.00 \\
86.67 \\
68.53\end{array}$ & $\begin{array}{l}51.67 \\
33.33 \\
90.00 \\
40.00 \\
71.67 \\
68.53\end{array}$ & $\begin{array}{c}86.67 \\
83.33 \\
80.00 \\
100 \\
93.33 \\
72.33\end{array}$ & $\begin{array}{c}81.67 \\
78.33 \\
81.67 \\
100 \\
83.33 \\
73.47\end{array}$ & $\begin{array}{c}86.67 \\
83.33 \\
83.33 \\
100 \\
88.33 \\
74.13\end{array}$ & $\begin{array}{l}98.33 \\
85.00 \\
65.00 \\
75.00 \\
75.00 \\
65.20\end{array}$ & $\begin{array}{l}96.67 \\
83.33 \\
68.33 \\
78.33 \\
75.00 \\
66.07\end{array}$ & $\begin{array}{l}91.67 \\
80.00 \\
68.33 \\
60.00 \\
66.67 \\
64.73\end{array}$ \\
\hline
\end{tabular}

Table 7. The percentage success rate of A, B and C measures on bitumen images grouped as Base, EBA (Elvaloy $\left.{ }^{\circledR} 3427\right)$, EVA (Evatene ${ }^{\circledR} 2805$, Elvaloy ${ }^{\circledR} 4170$ ), SBS (Kraton ${ }^{\circledR}$ D1101, Soltene ${ }^{\circledR}$ 6302) with $400 \times, 100 \times, 40 \times$ magnification.

\begin{tabular}{|c|c|c|c|c|c|c|c|c|c|}
\hline \multirow{2}{*}{ Polymer Type } & \multicolumn{3}{|c|}{$400 \times$} & \multicolumn{3}{|c|}{$100 \times$} & \multicolumn{3}{|c|}{$40 \times$} \\
\cline { 2 - 11 } & $\mathrm{A}$ & $\mathrm{B}$ & $\begin{array}{c}\mathrm{C} \\
(\%)\end{array}$ & $\begin{array}{c}\mathrm{A} \\
(\%)\end{array}$ & $\begin{array}{c}\mathrm{B} \\
(\%)\end{array}$ & $\begin{array}{c}\mathrm{C} \\
(\%)\end{array}$ & $\begin{array}{c}\mathrm{A} \\
(\%)\end{array}$ & $\begin{array}{c}\mathrm{B} \\
(\%)\end{array}$ & $\begin{array}{c}\mathrm{C} \\
(\%)\end{array}$ \\
\hline Base & 86.67 & 86.67 & 86.67 & 38.33 & 38.33 & 38.33 & 100 & 100 & 100 \\
EBA & 93.00 & 93.00 & 91.33 & 89.33 & 94.67 & 95.00 & 71.33 & 73.67 & 66.00 \\
EVA & 97.04 & 96.67 & 97.59 & 91.85 & 92.04 & 91.85 & 92.78 & 93.52 & 94.07 \\
SBS & 89.83 & 89.83 & 90.33 & 94.67 & 94.67 & 94.50 & 88.00 & 88.00 & 87.50 \\
Average & 91.63 & 91.54 & 91.48 & 78.55 & 79.93 & 79.92 & 88.03 & 88.80 & 86.89 \\
\hline
\end{tabular}

Table 8. Confusion matrices for 3 specific magnification - method combinations. Each row represents a query class and percentages of assigned classes.

\begin{tabular}{|c|c|c|c|c|c|c|c|c|c|c|c|c|}
\hline \multirow[t]{2}{*}{$\begin{array}{c}\text { Confusion } \\
\text { Matrices }\end{array}$} & \multicolumn{4}{|c|}{$\begin{array}{c}400 \times \\
\text { Method A }\end{array}$} & \multicolumn{4}{|c|}{$\begin{array}{c}100 \times \\
\text { Method B }\end{array}$} & \multicolumn{4}{|c|}{$\begin{array}{c}40 \times \\
\text { Method C }\end{array}$} \\
\hline & $\begin{array}{c}\text { Base } \\
(\%)\end{array}$ & $\begin{array}{c}\text { EBA } \\
(\%)\end{array}$ & $\begin{array}{c}\text { EVA } \\
(\%)\end{array}$ & $\begin{array}{l}\text { SBS } \\
(\%)\end{array}$ & $\begin{array}{l}\text { Base } \\
(\%)\end{array}$ & $\begin{array}{c}\text { EBA } \\
(\%)\end{array}$ & $\begin{array}{c}\text { EVA } \\
(\%)\end{array}$ & $\begin{array}{l}\text { SBS } \\
(\%)\end{array}$ & $\begin{array}{c}\text { Base } \\
(\%)\end{array}$ & $\begin{array}{c}\text { EBA } \\
(\%)\end{array}$ & $\begin{array}{c}\text { EVA } \\
(\%)\end{array}$ & $\begin{array}{l}\text { SBS } \\
(\%)\end{array}$ \\
\hline Base & 86.67 & 0.00 & 13.33 & 0.00 & 38.33 & 1.67 & 41.67 & 18.33 & 100 & 0.00 & 0.00 & 0.00 \\
\hline EBA & 0.00 & 93.00 & 3.00 & 4.00 & 0.33 & 94.67 & 4.33 & 0.67 & 0.00 & 66.00 & 31.33 & 2.67 \\
\hline EVA & 0.37 & 1.11 & 97.04 & 1.48 & 0.93 & 1.67 & 92.04 & 5.37 & 0.00 & 3.70 & 94.07 & 2.22 \\
\hline SBS & 0.00 & 1.00 & 9.17 & 89.83 & 0.50 & 0.00 & 4.83 & 94.67 & 0.00 & 0.33 & 12.17 & 87.5 \\
\hline
\end{tabular}


as shown in Table 5, for a $6 \%$ Soltene $^{\circledR} 6302$ sample, choosing $100 \times$ magnification and method $\mathrm{C}$ is the best choice to identify $6 \%$ class within the set of Soltene ${ }^{\circledR}$ 6302 samples. Although method A should be expected to result in inferior outcomes, in some cases it seems to outperform rotationally invariant methods. This is due to accidental matching of wrong classes while trying to normalize for dominant orientation. Method A performs poorly for textures that are oriented in different directions (e.g. $5 \%$ content of Evatene ${ }^{\circledR} 2805$ displayed at $400 \times$ magnification).

\section{Conclusions}

Textural features computed using Gabor filters are tested on microscopic images of SBS, EVA and EBA polymers for the three different classification tasks. The first test is performed to see how well the computed features represent the main characteristics of specified mixture rates within the group of samples that were modified by the same type of polymer. High success rates resulting from the test exhibits the possibility to precisely determine the mixture rate given only the images of bitumen samples modified by a specific type of polymer. Different success rates corresponding to different polymer types or contents (i.e. mixture rates) indicate some of the classes (i.e. mixture rate of a specific polymer type for the test) can be identified more precisely than others.

The second test is performed to see whether it is possible to identify a sample with a specific type and mixture rate among the whole data set comprising all available images. The results of the second test are particularly useful to observe how well a subclass can be identified with no prior knowledge about the type/amount of modification. It is shown that some of the subclasses can be identified at relatively high success rates.

Finally, the third test is performed to see the success rates when the query is performed to determine the type of modification. Based on the captured images of bitumen samples with an arbitrary amount of polymer, the type of the polymer can be classified.

The main purpose of this study is to show that the textural features extracted from images of polymer modified bitumen represent the significant structural characteristics of samples and therefore to enable discriminative operations. Imagebased tests using textural features are shown to be effective in analysis of polymer modified bitumen despite their low operational costs. These tests are capable of extracting information related to the type and rate of modification which is not available from mechanical and chemical tests.

This paper is a first step towards image-based identification of bitumen samples using textural features. The classes that need to be identified may correspond to a specific type of polymer or a specific content. Both of these cases may be considered vitally important for inspection of malpractice by an authority, or for maintaining quality standards by manufacturers. Textural analysis of polymer modified bitumen images is shown to be an effective and promising tool to serve for these purposes.

This study is a part of the project supported by the Scientific and Technological Research Council of Turkey (TUBİTAK), Under Grant No. MAG 104M559. The authors gratefully acknowledge to TUBITAK.

\section{References}

[1] U. Isacsson, X. Lu: 34 (1999) 3737-3745.

[2] G. Airey: 16 (2002) 473-487.

[3] A.L. Bull, W.C. Vonk: Shell Chemical Technical Manual 8 (1984) 15.

[4] G. King: 68 (1999) 32-69.

[5] R. Bates, R.Worch: Engineering Brief, No. 39, FAA, Washington DC, 1987.

[6] M. Petrou, P.G Sevilla: Wiley, 2006.

[7] X. Lu, U. Isacsson: 11 (1997) 23-32.

[8] J. Chen, M. Liao, M. Shiah: 14 (2002) 224-229.

[9] B. Brule, Y. Brion, B. Tanguy: 57 (1988) 41-64.

[10] G.D. Airey: 16 (2002) 473-487.

[11] V. Wegan: Danish Road Institute, 1996.

[12] D. Gabor: 93 (1946) 429-457.

[13] B.S. Manjunath, W.Y. Ma: 18 (1996) 837-842.

[14] J. Han, K.K. Ma: 25 (2007) 1474-1481.

[15] C.S. Sastry, M. Ravindranath, A.K. Pujari, B.L. Deekshatulu: 28 (2007) 293-300.

[16] Q. Iqbal, J.K. Aggarwal: 35 (2002) 2673-2686.

[17] U. Kandaswamy, D.A. Adjeroh, M.C. Lee: 43 (2005) 2075-2083.

[18] P.P. Raghu, B. Yegnanarayana: 5 (1996) 1625-1636.

[19] K.L. Mak, P. Peng: 24 (2008) 359-369.

[20] A. Kumar, G.K.H. Pang: 38 (2002) 425-440.

[21] D. Zhang, W.K. Kong, J. You, M. Wong: 25 (2003) 1041-1050.

[22] W.K. Kong, D. Zhang, W. Li: 36 (2003) 2339-2347.

[23] J. Zuo, N.A. Schmid, X. Chen: 2 (2007) 77-90.

[24] S.L.G.D. Oliveira, J.T.D. Assis: 4 (2006) 1-6.

[25] F. Benhammadi, M.N. Amirouche, H. Hentous, K.B. Beghdad, M. Aissani: 40 (2007) 189-197.

[26] A. Ross, A. Jain, J. Reisman: 36 (2003) 1661-1673.

[27] C. Liu, H. Wechsler: 11 (2004) 467-476.

[28] J. Xie, Y. Jiang, H.T. Tsui: 24 (2005) 45-57.

[29] Y. Zhan, D. Shen: 25 (2006) 256-272.

[30] A.K. Jain, N.K. Ratha, S. Lakshmanan: 30 (1997) 295-309.

[31] X. Wu, B. Bhanu: 6 (1997) 47-64.

[32] W. Chan, G. Coghill: 34 (2001) 2523-2532.

[33] H.E.S. Said, T.N. Tan, K.D. Baker: 33 (2000) 149-160.

[34] T.N. Tan: 20 (1998) 751-756.

[35] S. Arivazhagan, L. Ganesan, S.P. Priyal: 27 (2006) 1976-1982.

[36] J.K. Kamarainen, V. Kyrki, H. Kalviainen: 15 (2006) 1088-1099.

[37] J. Han, K.K. Ma: 25 (2007) 1474-1481.

[38] F. Lahajnar, S. Kovacic: 24 (2003) 1151-1161.

[39] G.M. Haley, B.S. Manjunath: 8 (1999) 255-269.

[40] R. Porter, N. Canagarajah: 144 (1997) 180-188.

[41] T.M. Cover, P.E. Hart: 13 (1967) 21-27.

(Received September 24, 2010; accepted March 2, 2011)

\section{Bibliography}

DOI $10.3139 / 146.110510$

Int. J. Mat. Res. (formerly Z. Metallkd.)

102 (2011) 5; page 513-520

(C) Carl Hanser Verlag GmbH \& Co. KG

ISSN 1862-5282

\section{Correspondence address}

Asst. Prof. Dr. Ali Topal

Dokuz Eylul University

Faculty of Engineering

Department of Civil Engineering

35160, Tinaztepe Campus, Buca-Izmir, Turkey

Tel.: +902324127040

Fax: +902324127253

E-mail: ali.topal@deu.edu.tr

You will find the article and additional material by entering the document number MK110510 on our website at www.ijmr.de 